\title{
DESIGN MOTIVATION, MECHANICAL MODELING AND NONLINEAR ANALYSIS OF COMPOSITE PR MOMENT FRAMES WITH SMART SMA CONNECTION SYSTEMS
}

\author{
Jong Wan $\mathrm{Hu}$ \\ Assistant Professor, Department of Civil and Environmental Engineering, College of Urban Science, \\ University of Incheon, Incheon, 406-840, Republic of Korea \\ (Head of Center, Incheon Disaster Prevention Research Center, University of Incheon, Incheon, 406-840, \\ Republic of Korea) \\ E-mail: jongp24@incheon.ac.kr
}

Received: 27 March 2012; Revised: 8 July 2012; Accepted: 13 July 2012

\begin{abstract}
This paper focuses on seismic design and behavior of hybrid structures composed of partially restrained (PR) steel-concrete composite-moment frames (C-MFs). The innovative aspects of this research are to introduce new smart connections between steel beams and concrete-filled tube (CFT) columns that utilize a combination of low-carbon steel and shape memory alloy (SMA) components in the C-MF design. In these new connections, we can exploit the recentering effect provided by super-elastic SMA tension bars to reduce both building damage and residual drift after a major earthquake event, while the low-carbon steel components provide excellent energy dissipation. The results of corresponding component tests were used to develop cyclic stiffness models for individual components in the connection. The seismic behavior of the composite moment-resisting frames with new connection systems was reproduced by performing nonlinear pushover and time-history analyses. The analysis results suggest that these frames are very effective in resisting seismic events due to the structural advantages of the smart SMA PR-CFT connections.
\end{abstract}

Keywords: Composite moment frames, Shape memory alloys (SMAs), Partially restrained (PR) connections, Concrete-filled tube (CFT) columns, Stiffness models, Mechanical modeling, Nonlinear frame analyses

\section{INTRODUCTION}

Composite-partially restrained frames (C-PRMFs) are composed of I-shape steel beams and composite concrete-filled steel tube (CFT) columns, which are interconnected with PR composite connections (e.g. Tsai et al. [1]; Wu et al. [2]). The C-PRMFs were originally proposed for use in the areas of low to moderate seismicity, classified as seismic design categories (SDC) $\mathrm{C}$ and below (e.g. AISC (2005) [3]; ASCE [4]). However, they can be utilized at the areas of higher seismicity in the western United States (SDC D and over) with appropriate detailing and analysis. Recently developed bidirectional bolted CFT column-to-beam connections have been widely used in modern steel structures because they provide superior seismic performance with respect to strength, ductility, energy dissipative capacity, and stiffness (e.g. Wu et al. [2]; Wu et al. [5]; Park et al. [6]; $\mathrm{Hu}$ et al. [7]). Studies have demonstrated that their seismic resistance exceeds requirements stipulated in the seismic design codes of Taiwan and US (e.g. Tsai et al. [1]; Wu et al. [2]; Wu et al. [5]). T-sub connections were used as the main component for the composite bolted PR-CFT connections used in this study (see Figure 1).

For the smart PR-CFT connections proposed in this study, three design concepts were integrated: (a) the use of CFT columns, (b) the use of PR connections, and (c) the introduction of new smart materials (i.e. Shape memory alloys). Mixed or hybrid systems such as CFT columns combine the synergetic advantages of ductility and toughness associated with steel structures and high compressive strength associated with confined concrete components. CFT columns in the moment resisting frame are very suitable as the vertical elements to resist high gravity loading because they have a high strength-to-weight ratio (e.g. Tsai et al. [1]; Wu et al. [5]; Park et al. [6]; Hu et al. [7]). 
They are especially efficient in high seismic areas because of excellent dynamic resistance under biaxial bending plus axial force and good damping characteristics (e.g. Hu et al. [8]). Moreover, the steel tube can be used as a formwork for casting concrete; therefore, this design improves constructability over conventional reinforced concrete structures. CFT columns have gained wide acceptance in China, Japan, Korea, Taiwan, and in some areas of the USA for use in high-rise construction. Circular and rectangular shapes can be used in CFT column sections (CCFT or RCFT).
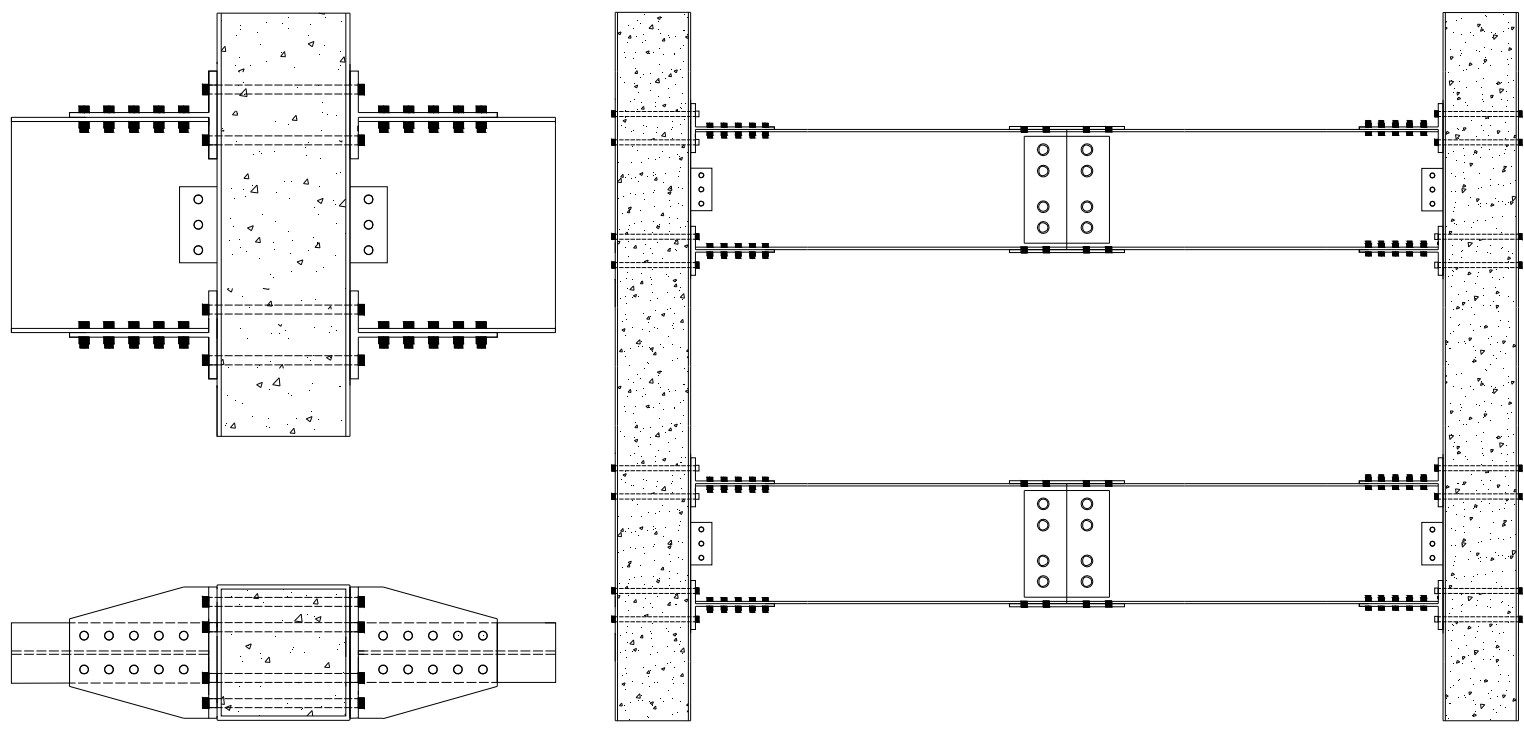

(a) Composite bolted PR-CFT connection

(b) Composite PR moment frames (C-PRMF) using PR-CFT connections

Figures 1 (a) and (b). Connection Details and Composite PR Moment Frames (C-PRMF)

Major failures of fully restrained (FR) moment frames with welds during the 1994 Northridge and 1995 Kobe earthquakes led to the conclusion that traditional buildings suffer from brittle fracture problems in the moment connections (e.g. Leon [9]). When using PR connections, improved performance is derived from a combination of (a) a decrease in the seismic forces stemming from the additional flexibility of component members due to the PR nature of the connections, and (b) an increase in the structural strength reserve capacity due to the lack of brittle connection failure modes. Although PR connections are not as stiff as FR connections, it has been demonstrated that well-detailed PR structures can provide similar or superior seismic behavior compared to their FR counterparts (e.g. Leon [9]; Green et al. [10]; Rassati et al. [11]).

More recently, beam-to-column connections using super-elastic (SE) Nitinol (NiTi) tendons have been investigated at the Georgia Institute of Technology (Georgia, USA). The goal is to use these new materials in the design of moment connections (e.g. Penar [12]; Hu [13]). SE Nitinol is a type of SMA with the unique ability to sustain large strain that is fully reversible, thereby automatically returning the structural element to its original position without residual deformation when stresses are removed, as shown in Figure 2 (e.g. DesRoches et al. [14]). The characteristics of the stress-strain curve largely depend on a phase transformation process that is controlled by heat treatment and chemical composition. A recentering effect from the connections can be expected due to the SE effect of these new materials. 

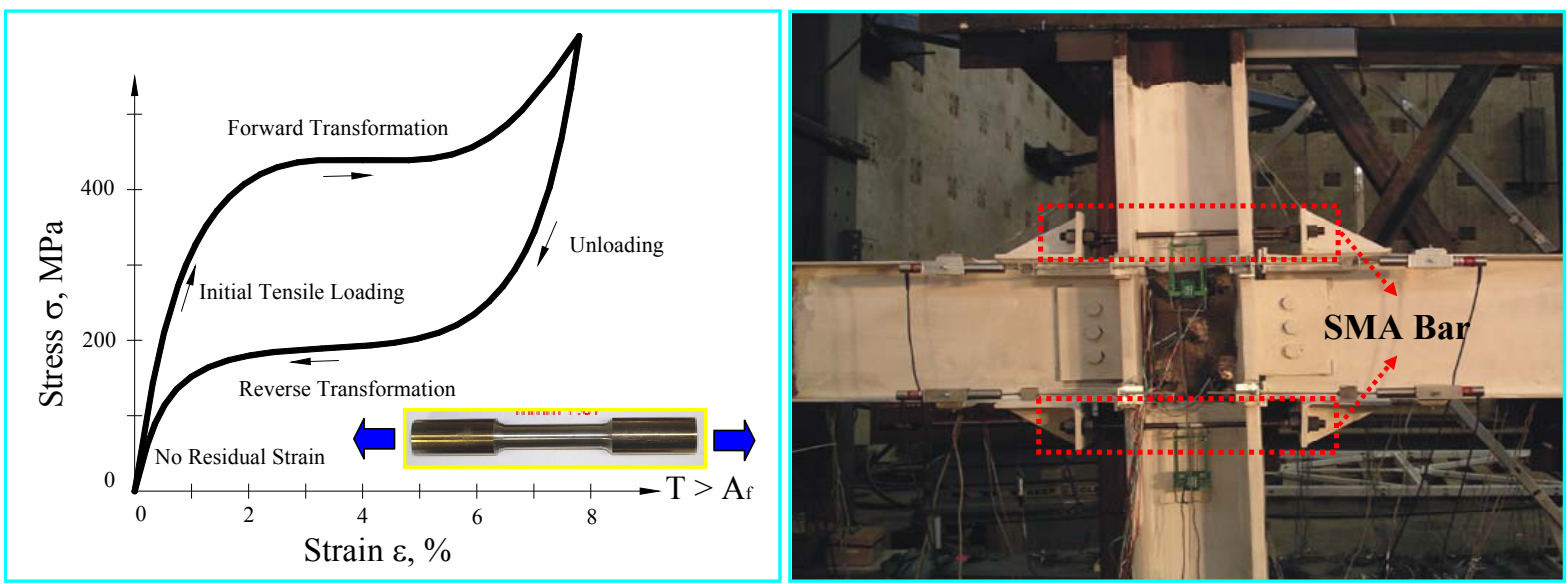

Figure 2. Stress and Strain Behavior and Connection Application for Super-elastic (SE) SMA Materials (e.g. DesRoches et al. [14])

A new type of connection, which is called the SMA PR-CFT connection in this study (see Figure 3), combines the advantages of bolted PR connections, new smart SMA materials, and the aforementioned composite structures. Contrary to the existing PR connection, this new connection exploits the combination of steel bars and SE Nitinol bars as connection elements to CFT columns. The combination of CFT columns, SMA bars, and PR connections will achieve upgraded strength, local buckling prevention, recentering capability, and excellent ductility.

This paper is divided into three parts. We describe (a) a simplified two dimensional (2D) joint model for cyclic tests, (b) numerical composite-moment frame models with joint models, and (c) nonlinear frame analyses. The seismic performance of the composite moment frame with the proposed SMA PR-CFT connections is compared with the seismic performance of other composite moment frames with commonly used connections in order to show the adequacy of numerical simulations and the structural advantage of the proposed connection design. Most of the numerical tests were performed using finite element (FE) models for connections and composite frames using the OpenSEES program (e.g. Mazzoni et al. [15]).

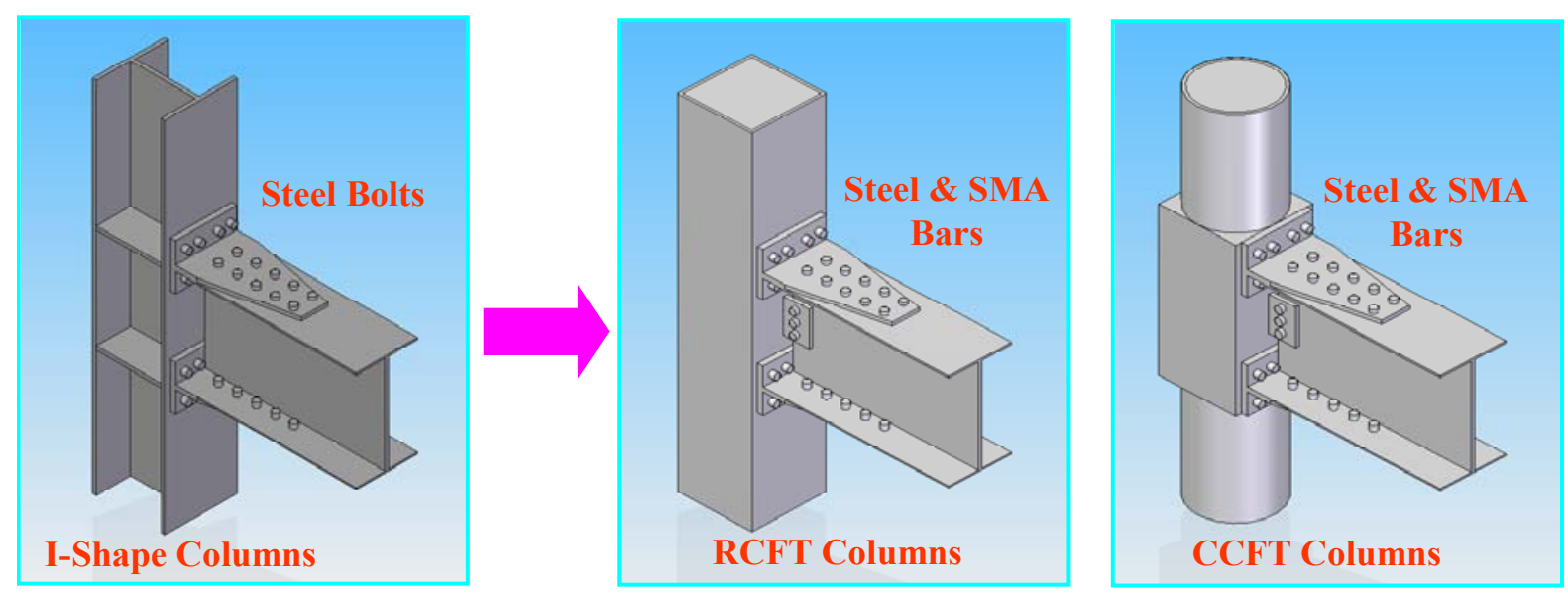

Figure 3. New Smart PR-CFT Connections Compared with the Previous PR Connection 


\section{JOINT MODEL}

Joint models suitable for use in nonlinear frame analyses are able to accurately reproduce the inelastic response of moment frame structures under cyclic loading. In this study, joints were modeled as user-defined 2D joint elements that are composed of assemblies of springs, linked to each other in series or parallel to mimic the connection behavior. The primary purpose is to develop simplified, numerically efficient, accurate joint models that simulate the real non-linear connection, and frame behavior.

\subsection{Basic Mechanisms}

A moment frame structure should provide adequate stiffness, strength, and energy dissipation capacity to withstand both gravity loads and lateral loads. The random seismic inertial forces introduced into a building by an earthquake can be converted into a set of equivalent lateral loads for design (e.g. ASCE [4]). As lateral loads dominate the behavior, the joints are mostly deformed in a shear mode (a scissors-line manner) due to double curvature bending. The double curvature moments resulting from lateral loads are delivered into the connections as equivalent axial forces (e.g. Braconi et al. [16]).

Figure 4 show the idealized force distribution at the perimeter of the joint for a T-stub connection subjected to seismic loads. Connection components such as tension bars, flanges, T-stems, and shear tabs were modeled as corresponding nonlinear-axial or nonlinear-rotational spring elements. The slip mechanism was simulated using sliding elements (see Figure 4 (b)). Generally, the beam develops flexural strength, while the column carries the axial gravity loads elastically. These member forces are shown as equivalent concentrated forces acting on the joint (see blue arrows in Figure 4 (a)). The internal reactions in the connection components (see yellowish green arrows in Figure 4 (b)) act against these converted external forces to satisfy force equilibrium $\left(\Sigma \mathrm{B}_{\mathrm{i}}=\mathrm{P}\right)$.

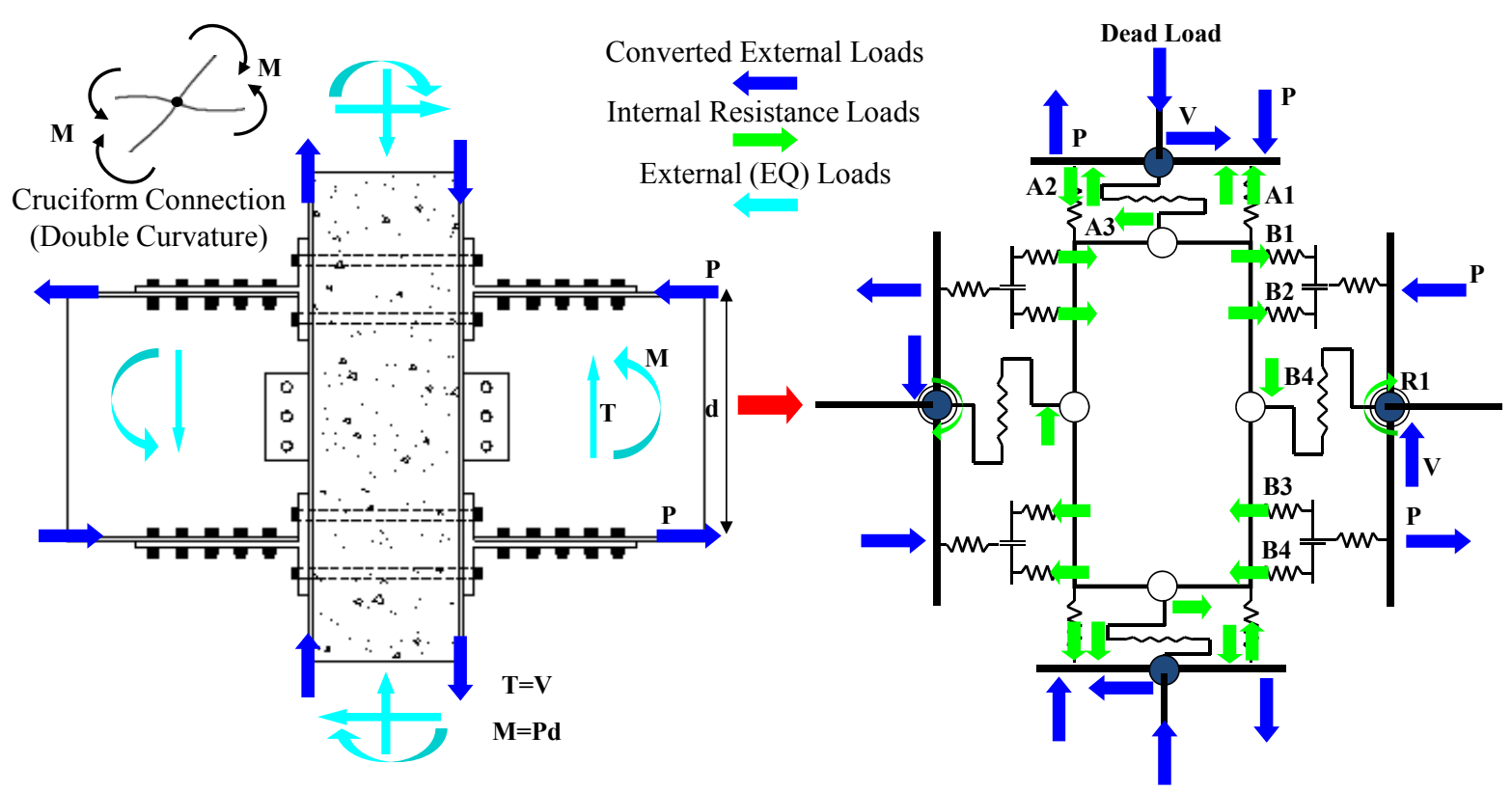

(a) Idealized loading distribution at the PZ

(b) Idealized loading distribution at the joint model

Figures 4 (a) and (b). Force Distribution at the Joint Model for the Composite PR-CFT Connection 
The response of the joint model under shear deformations resulting from the bending forces in the framing members is shown in Figure 5. The internal tension loads are carried by tension bars, which correspond to the top springs on the right side of the connection, as shown in Figure 5 (a). Internal compression loads resulting from the bearing forces between the beam flange and the CFT column surface are transferred into the bottom springs on the right side of the connection. The bars inside the compression zone do not produce a significant contribution to the response mechanism of the joint model. The deformations of the tension bars located above bearing compression are proportional to their distance from the centerline of the bottom flange $\left(\Delta=\Delta_{\mathrm{i}} \mathrm{h} / \mathrm{h}_{\mathrm{i}}\right)$.

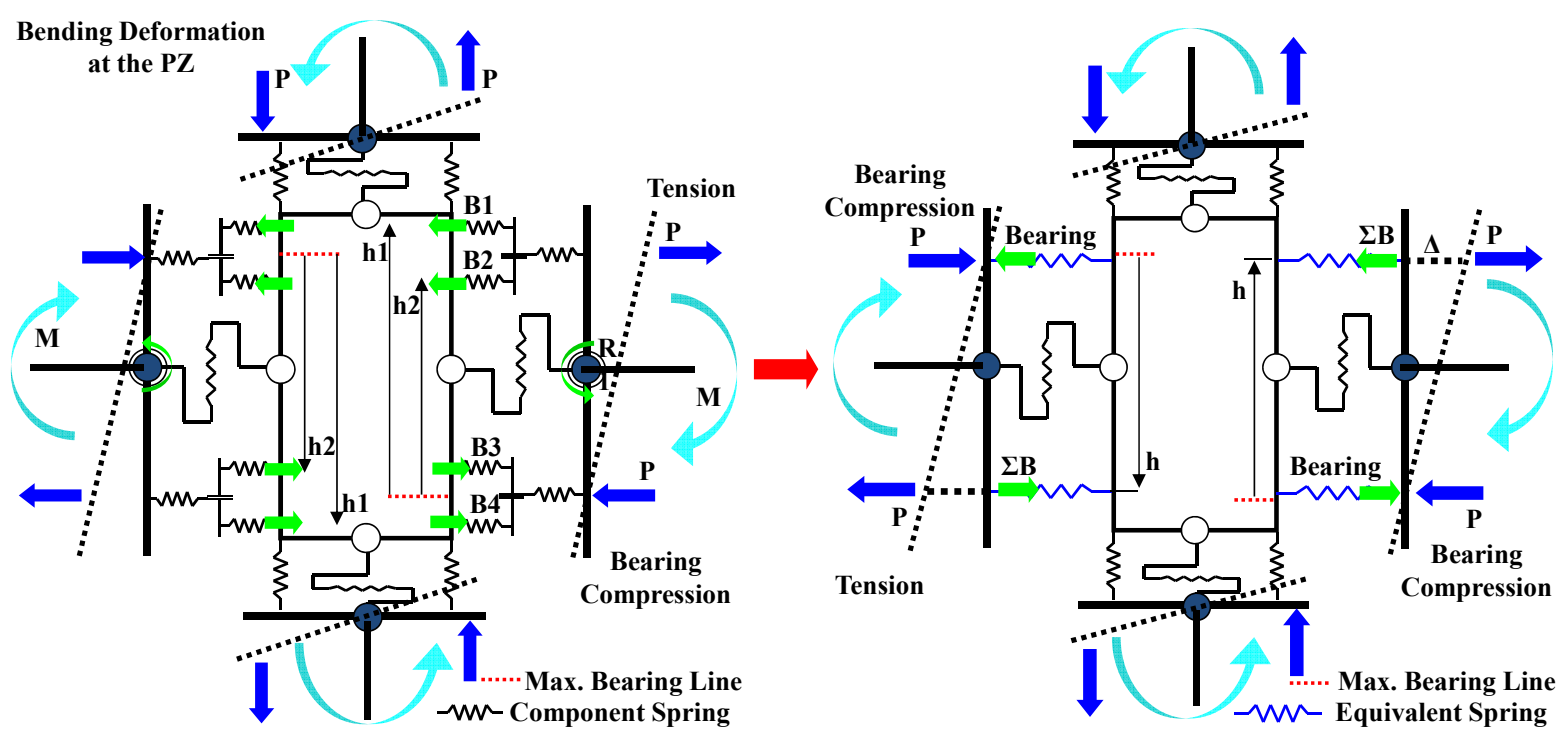

(a) Bending deformation at the joint model with component spring elements

(b) Bending deformation at the simplified joint model with equivalent spring elements

Figures 5 (a) and (b). Force and Deformation Response Mechanism of the Joint Model

\subsection{Component Springs}

Detailed procedures for the formation of an equivalent spring element are illustrated in Figure 6, including the behavior of individual component springs. The main properties are modeled as idealized stiffnesses, as presented in Figure 6 (a). The stiffness models for tension bars were determined from their own material properties, whereas those for bearing compression, T-stem deformation, and slip-sliding were obtained via established stiffness models (e.g. Kurak et al. [17]; Rex and Easterling [18]; Astaneh-Asl [19]; Hu et al. [20] ) and curve fitting to existing test data (e.g. Swanson [21]; Swanson [22] ) (see Figure 6 (c)). For numerical analyses, the curves were generated using default material commands available in the OpenSEES program. The behavioral properties for slip springs and T-stem springs were generated using pinching materials and steel hardening materials, respectively (e.g. Mazzoni et al. [15]). The stiffness model for the superelastic SMA materials, on the other hand, was simulated by user-defined material codes (e.g. Davide [23]) because an appropriate material command was not available in the program. These stiffness models were assigned to corresponding component springs to simulate the behavior of component members during cyclic loading tests. 


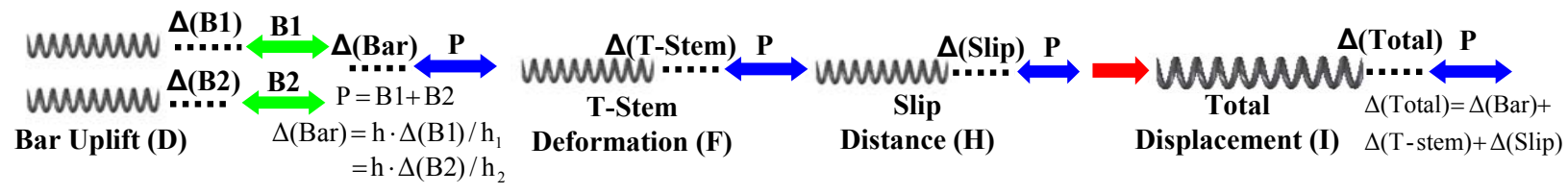

(b) The assemblage of the spring components

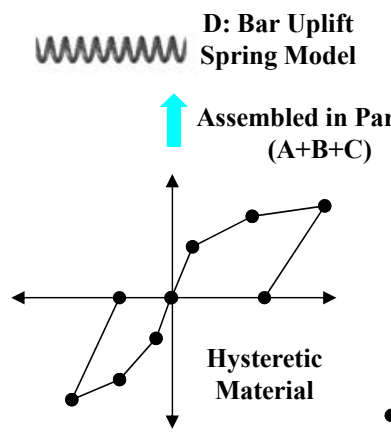

WhW C: Steel Bar Spring

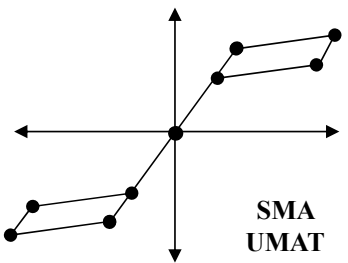

WUCWW B: SMA Bar Spring
WunW H: Slip Spring

Assembled in Parallel (G)

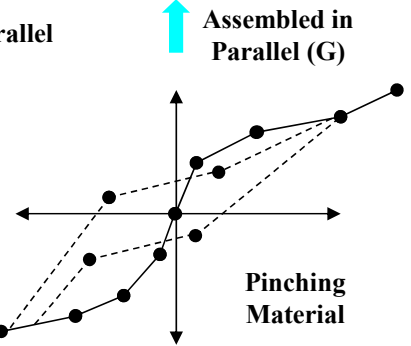

WUWUW G: Slip Spring

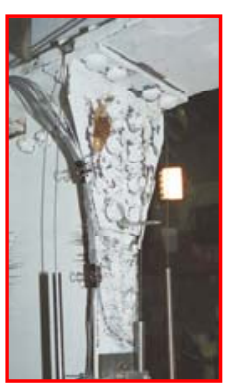

Experiment Mode (Swanson, 2002)

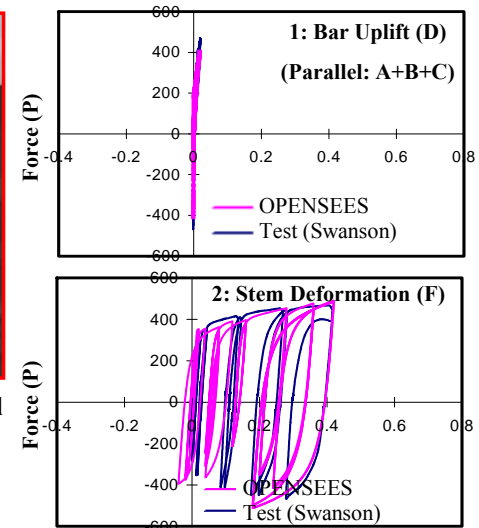

Model

munch

Assembled in Series One Equivalent $(\mathbf{D}+\mathbf{F}+\mathrm{H}) \quad$ Spring

Wunch F: T-Stem Spring Model

Assembled in Parallel (E)

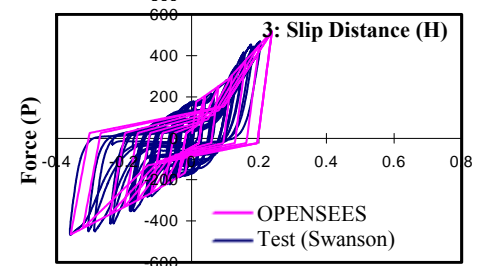

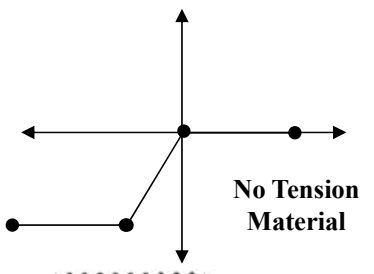

WunCW A: Bearing Spring

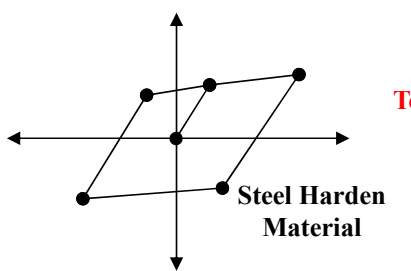

WCWOW E: T-Stem Spring

(a) The behavioral property of individual components
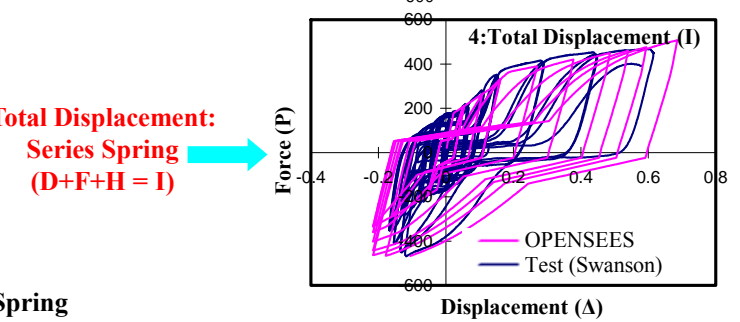

(c) The calibration of stiffness models to experimental results

Figures 6 (a), (b), and (c). Behavioral Properties and Assembly Procedures for the Component Spring Elements

The total displacement of the T-stub was constructed by adding the deformations from three basic mechanisms together under the converted axial load (P). The mechanisms are (a) bar uplift and flexural deformation of the T-flange, (b) T-stem deformation, and (c) slip. The individual basic mechanisms occurring in the connection components were ideally modeled by using nonlinear spring elements. These different spring elements in the connection component can be assembled in parallel or series depending on how they interact with each other (see Figures 6 (a) and (b)). This methodology offers the possibility of component assemblies and condensed-mechanical models so as to achieve a simplified model for numerical analyses. The response mechanisms acting on the tension bars were combined in parallel so that internal bar reaction forces correspond to the converted axial force $(\mathrm{B} 1+\mathrm{B} 2=\mathrm{P})$. As this converted axial force $(\mathrm{P})$ was transmitted into consecutive component springs, each of the deformations was added to the total displacement by the use of a series system $(\Delta($ Bar $)+\Delta($ T-stem $)+\Delta($ Slip $)=\Delta$ (Total) $)$. Their stiffnesses were also assembled into the final, total rigidity, which is the overall stiffness of the T-stub component. Therefore, the total displacement of the T-stub component was simulated through a cyclic loading test carried out by using the equivalent spring element as can be seen in Figure 6 (c). Furthermore, the cyclic curves reproduced by using the spring elements were compared with the resulting curves obtained from the experimental component tests in an effort to validate the component spring 
element model for simulation. The experimental component tests were performed by Swanson (e.g. Swanson [21]). In this study, the TA01 specimen for the experimental test was selected for comparison. Both results compared to each other show good agreements in terms of initial stiffness, shape of the envelope, ultimate capacity, and even location of pinching points, and thus result in a good visual match of the shape of the hysteresis loops.

\subsection{User-defined 2D Joint Elements}

The data from experimental connection tests (e.g. Swanson [21]) were employed to develop a simplified 2D joint element for use in the OpenSEES program. This program allows the implementation of refined joint elements such as the one proposed herein as shown in Figure 7. The composition of the joint element for a general beam-to-column connection is illustrated in this figure. This element includes (a) two equivalent spring elements (S1) to reproduce the behavior of the connection components, (b) six internal spring elements (S2) to reproduce the axial deformation of the CFT column, (c) four internal shear springs (S3) to reproduce the shear deformation of the CFT column and the beam, (d) one shear panel zone element $(\mathrm{C})$ to reproduce the failure of the panel zone under severe loading, and (e) two rotational spring elements (D) that are intended to reproduce the shear deformation at the composite panel zone (e.g. Hu [13]). Additional rotational spring elements can be used if shear tabs are present in the connection model. All spring elements were formulated using zero-length elements with their stiffness properties. Thus, they are implemented with the interior and exterior planes coincident.
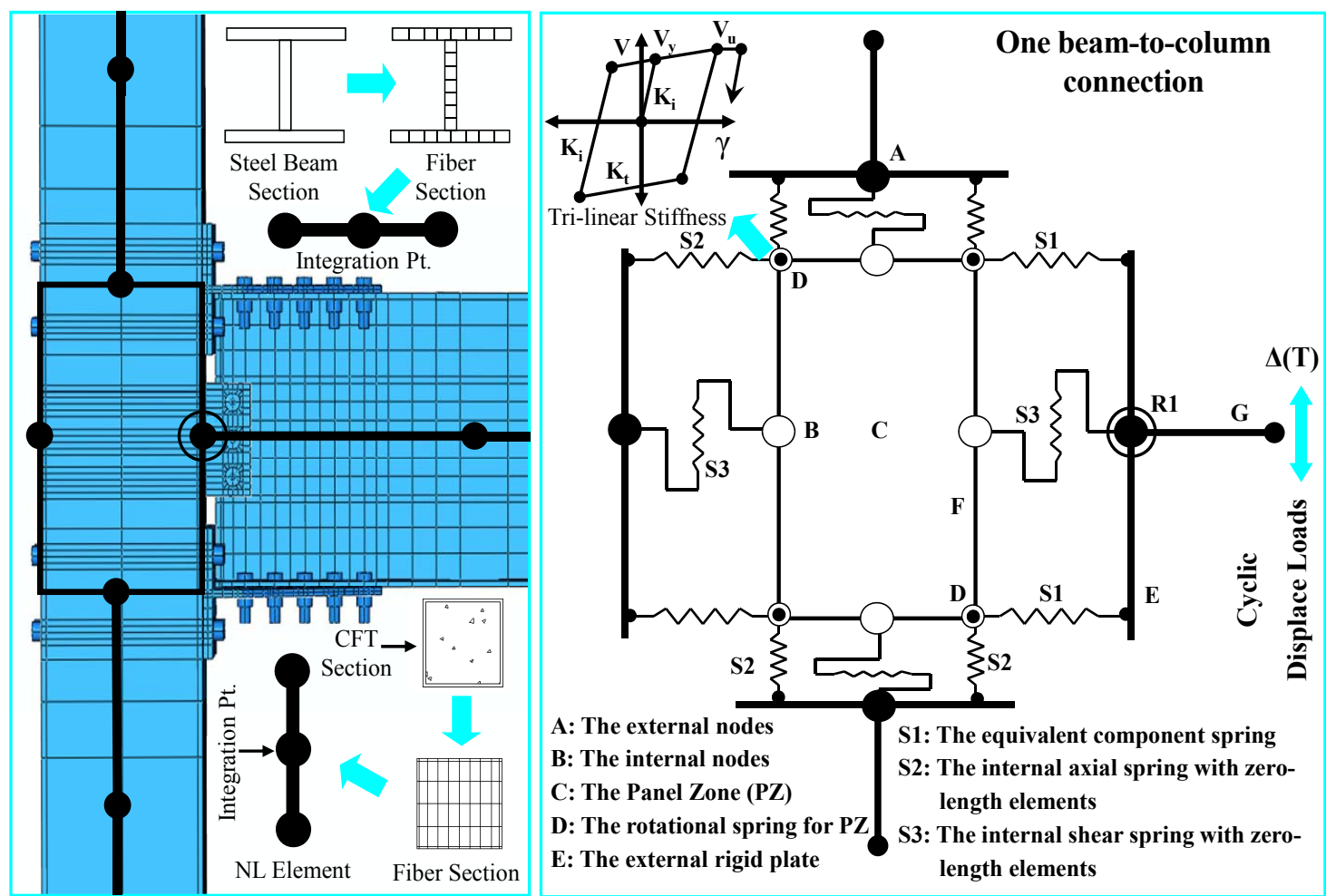

(a) The element formulation on the connection (b) The joint element of one beam-to-column connection

Figures 7 (a) and (b). Typical Joint Element for a Joint Model (One Beam-to-column Connection) (e.g. $\mathrm{Hu}[13])$ 


\section{NUMERICAL MODELS FOR COMPOSIT-MOMENT FRAMES}

\subsection{Connection Design}

The connections were fabricated with an assembly of various members cut from standard shapes provided in the current design specification (e.g., AISC [3]). A572 Grade 50 steel with strain hardening was used for beam members, shear tabs, and T-stub components. The T-stub connections accepted herein were composed of thick T-stub components cut from a W16X100 section and 114 X228X14mm plate for the shear tabs. Standard tube sections constructed with A500 Grade C steel material were used for CFT columns. A490 high strength bolt material was used to fabricate steel bars, washers, and nuts. The diameter of web and shear bolts was $25 \mathrm{~mm}$. For the purpose of maximizing the recentering mechanism, super-elastic SMA bars were installed at the parts where large deformations were feasibly to occur. The panel zones were designed as rectangular shape in order to allow for bidirectional T-stub connections with steel and SMA tension bars completely running through the connections. These tension bars include $25 \mathrm{~mm}$ diameter, either $510 \mathrm{~mm}$ length for RCFT columns or $560 \mathrm{~mm}$ one for CCFT columns. The details for connection design are described in Figure 8.

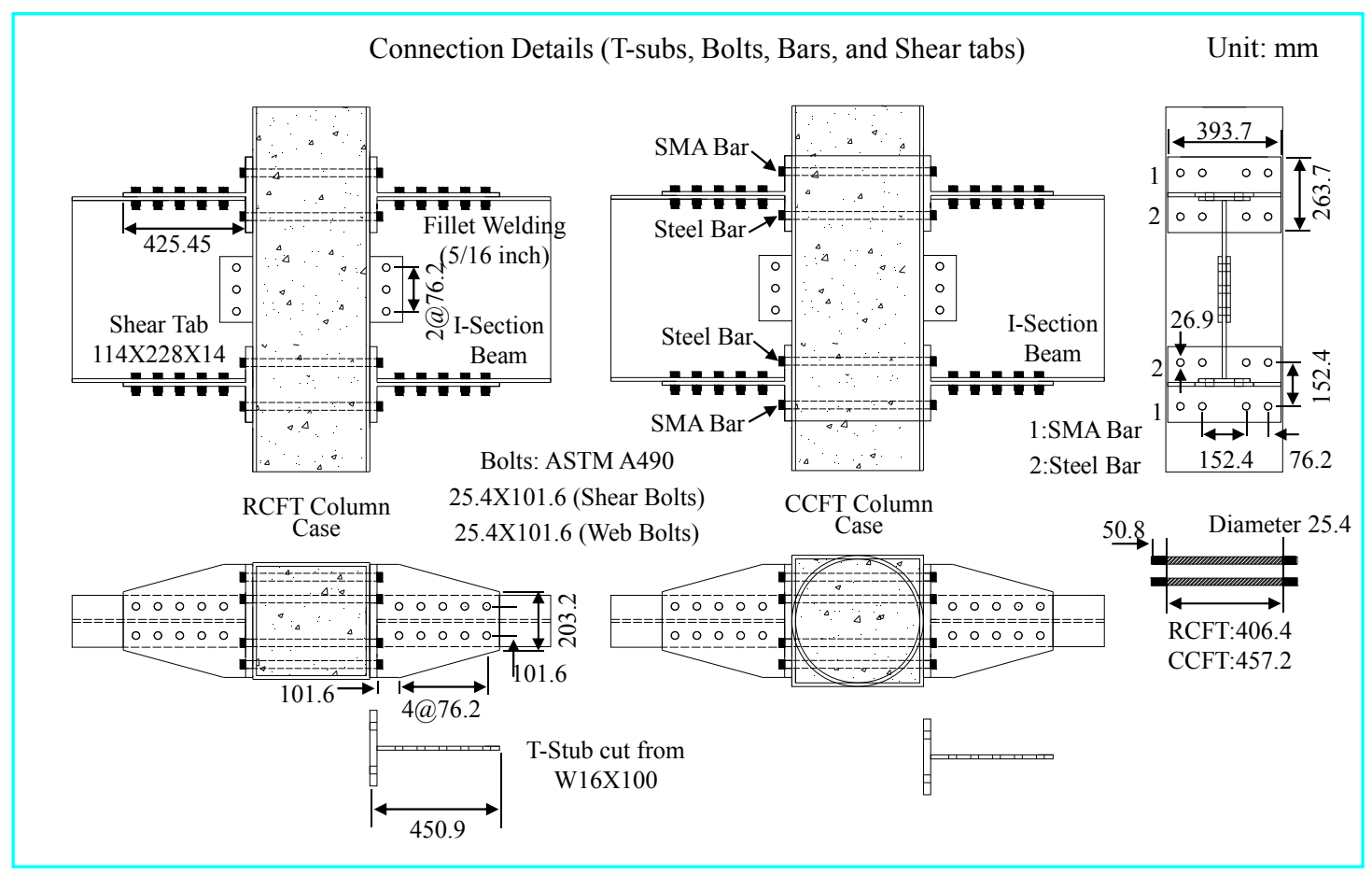

Figure 8. Details of the Connection Models (T-stubs, Bolts, Bars, and Shear Tabs)

\subsection{Frame Design}

All buildings were designed as 6-story composite structures with 3 by 5 long bays, and were located in the Los-Angeles (LA) area. Consistent dead loads, live loads, seismic design category (SDC), and occupancy category were used for all buildings. Based on the mapped maximum spectral acceleration in the LA area, the SDC for LA area was assumed to be as defined for the D class in the IBC 2003 code (e.g. ICC [24]). The composite-moment frames have a 9.15- $\mathrm{m}$ by 7.63-m span length with a 3.97-m story height (see Figure 9). The CFT columns were considered to be fixed at the basement. Perimeter moment resisting frames were used to resist all lateral loads. Overall, all buildings had a symmetric configuration at all story levels. 


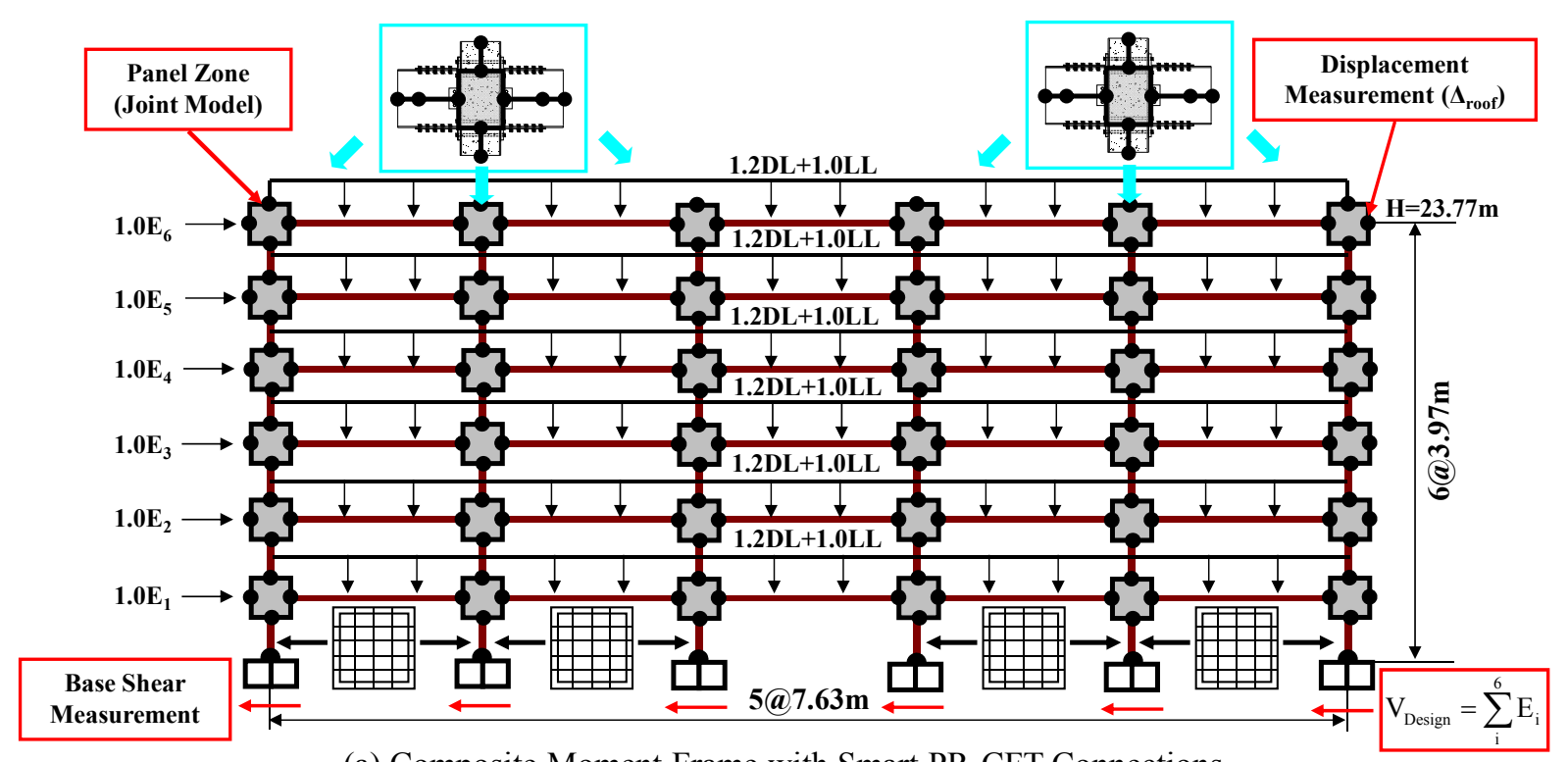

(a) Composite Moment Frame with Smart PR-CFT Connections

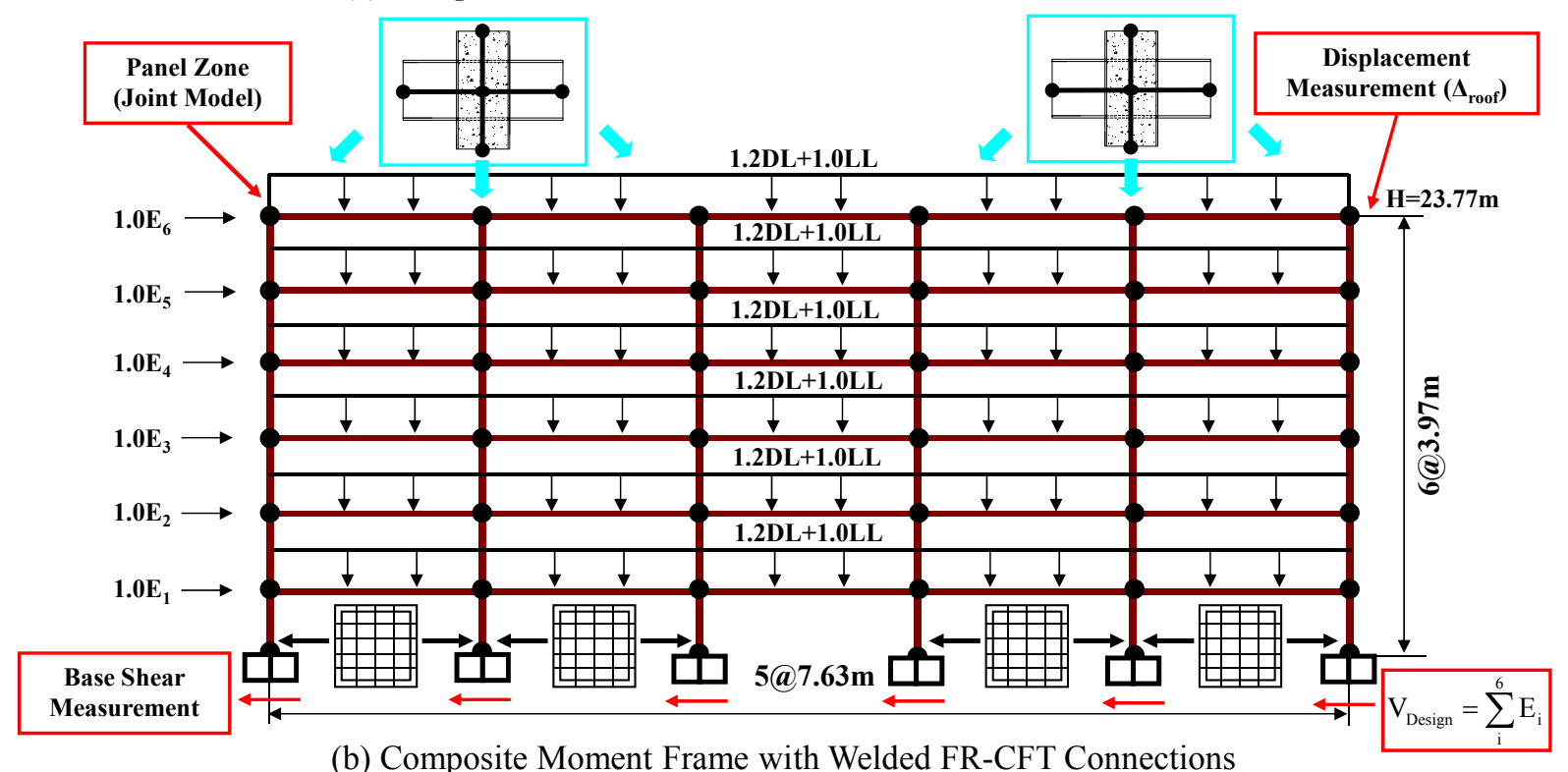

Figures 9 (a) and (b). Modeling Attributes for Load Combination, Response Measurement, Panel Zone, and Elevation View

The composite frame members were designed in accordance with the AISC-LRFD specification (e.g. AISC [25]) and the AISC 2005 Seismic Provisions (e.g. AISC [3]). The steel beams were designed with two different member sizes, W24X62 and W24X55, according to the story level. The CFT columns were continuous for all story frames. Member sizes and design details are given in Table 1. In this table, the number 6 shown in the model ID indicates the total number of stories. The letter of the acronym following this number indicates the connection types used: the new PR-CFT connections (PRT: Partially restrained T-stub connections) or welded connections (FRW: Fully restrained welded connections). The last identifier (RC or $\mathrm{CC}$ ) represents the model combination determined by the CFT column system $(\mathrm{RCFT}=\mathrm{RC}$ and $\mathrm{CCFT}=\mathrm{CC})$. The ideal failure mode by the full plastic yielding of beam members after the considerable hardening of the connections was expected for the C-PRMF models. 
Table1. Design Results for Composite Frame Buildings

\begin{tabular}{cccccc}
\hline $\begin{array}{c}\text { Model } \\
\text { ID }\end{array}$ & $\begin{array}{c}\text { Connection } \\
\text { Type }\end{array}$ & Column & Column Size & \multicolumn{2}{c}{ Beam Size } \\
System & (All Stories) & $1^{\text {st }}$ to $3^{\text {rd }}$ Story & $4^{\text {th }}$ and 6 ${ }^{\text {th }}$ Story \\
\hline 6PRT-RC & T-Stub & RCFT & HSS16X16X375 & W24X62 & W24X55 \\
6PRT-CC & T-Stub & CCFT & HSS18X375 & W24X62 & W24X55 \\
6FRW-RC & Welded & RCFT & HSS16X16X375 & W24X62 & W24X55 \\
6FRW-CC & Welded & CCFT & HSS18X375 & W24X62 & W24X55 \\
\hline
\end{tabular}

\subsection{Numerical Frame Models}

In the building plan, composite floors have symmetric configurations at all story levels and behave as rigid diaphragms. Therefore, perimeter moment resisting frames have the same lateral deformation as all internal frames under lateral forces and 3D building models can be replaced with 2D frame models. The modeling attributes for the 2D numerical frame models are given with more details in Figure 9. Perimeter moment resisting frames along the W-E direction were used for nonlinear frame analyses.

The modeling attributes for elements, fiber sections, and material models follows the previous studies for local connection models (check Secs. 2.2 and 2.3). Thus, steel beams and CFT columns were modeled as nonlinear beam-column elements with 2D fiber sections and nonlinear uni-axial materials. For the C-PRMF models (e.g. 6PRT-RC and -CC), composite panel zones were modeled using 2D joint elements to introduce the new smart PR-CFT connections into these numerical frame models (see Figure 9 (a)). The connections for the welded composite moment frames (e.g. 6FRW-RC and -CC) were modeled with the beam flange, web, or entire cross section penetrating though the composite column. Welded FR-CFT connections were assumed to be fixed where the nodal points of the beam elements were directly attached to those of the column elements, as shown in Figure 9 (b). The size of the welded panel zones was controlled by the rigid-end offsets.

In our nonlinear pushover analyses, earthquake or wind loads were converted into a set of equivalent lateral loads $\left(\mathrm{E}_{\mathrm{i}}\right)$ as stipulated by the ASCE 07-02 (e.g. ASCE [4]). The determination of these equivalent lateral forces depends on several code design factors such as ground motion parameters, site classification, the classification of the structural system, and the fundamental period of vibration. They were determined from Sections 9.4 and 9.5 in the ASCE 07-02. The summation of static lateral forces results in the design seismic base shear $\left(\mathrm{V}_{\text {Design }}\right)$. The design dead loads (DL) and live loads (LL) were assumed as $4.74 \mathrm{kPa}$ and $3.83 \mathrm{kPa}$, respectively. As stipulated in the ASCE 07-02, the load combination 5 (LC 5: 1.2DL+1.0 $\mathrm{E}_{\mathrm{i}}+1.0 \mathrm{LL}$ ), which commonly dominated over other load combinations was used for the nonlinear pushover analyses. At the C-PRMF model (i.e. 6PRT-RC model), the force-deformation curves of individual components under static pushover are given as a reference in Figure 10.

For nonlinear dynamic analyses, a long time period ground motion (e.g., LA 21) assuming a 2.0\% probability of exceedance in 50 year was used. This ground motion was constructed from historical records for the western US area (e.g. Somerville et al. [26]). As commonly recommended for code-designed frame buildings (e.g. ASCE [4]; ICC [24]), lumped masses composed of 1.0 times dead loads plus 0.2 times live loads were taken into consideration. To solve the time dependent-dynamic problem, a transient equilibrium analysis was performed using the Newmark method (e.g. Newmark [27]). A value of $2.5 \%$ was used for the damping as defined by the Rayleigh 
command in the OpenSEES program. It ensures that this damping ratio is slightly greater than the recommended value of $2.0 \%$ for reinforced concrete (RC) frames (e.g. Mazzoni et al. [15]). The second-order effects (P-Delta effect) due to gravity loads were also taken into consideration by adding dead loads and live loads to the beam elements. The data of interest such as nodal displacements, member forces, and base shear forces were collected using the recorder command in the program.

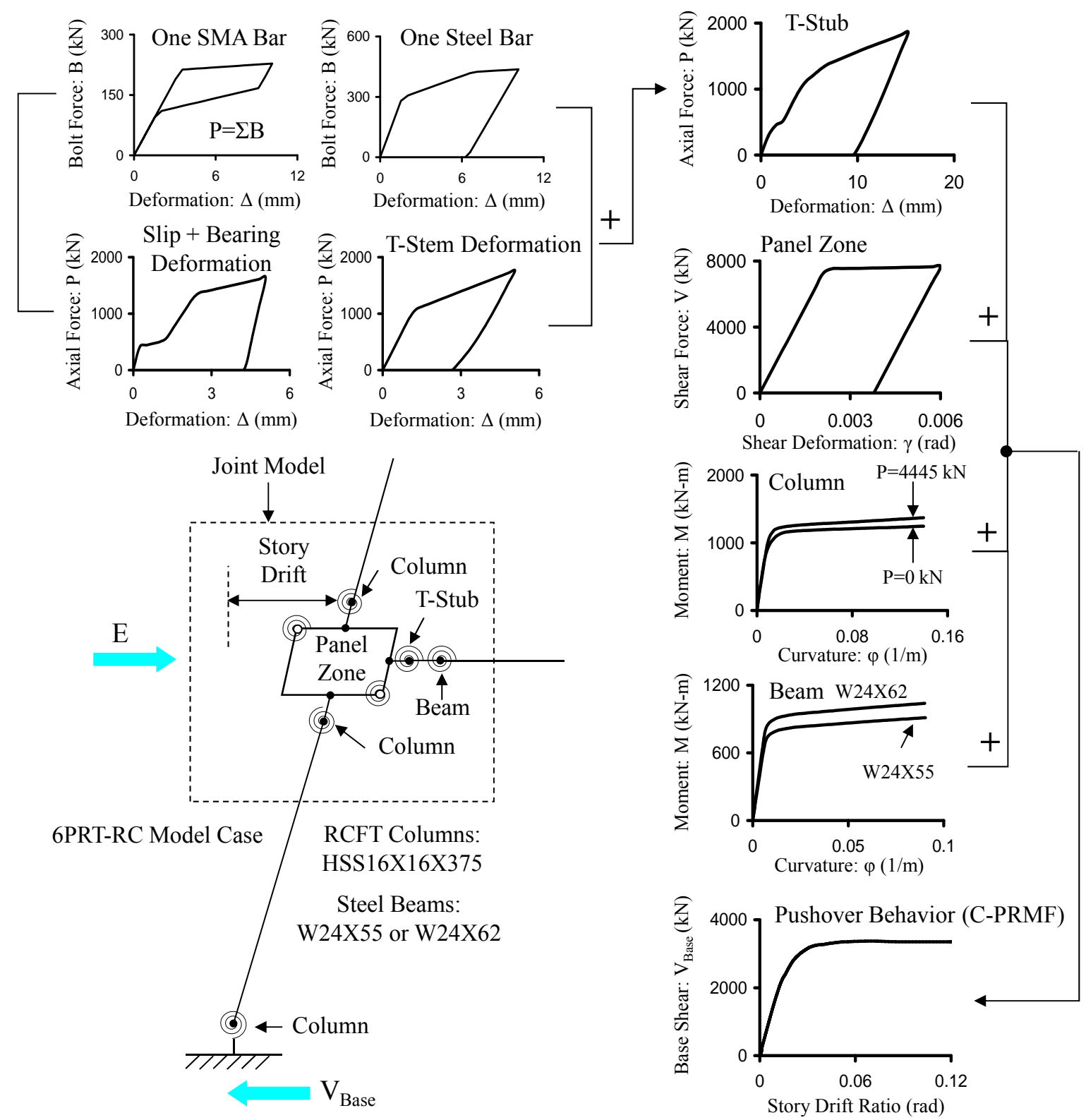

Figure 10. Force-deformation Curves of Individual Components under Static Pushover (6PRT-RC Model Case)

\section{NONLINEAR ANALYSES AND PERFORMANCE EVALUATIONS}

\subsection{Nonlinear Pushover Analyses}

2D nonlinear pushover analyses were conducted on the numerical frame models developed herein to evaluate lateral strength and deformation behavior. The force and deformation relationships obtained from static or cyclic pushover analyses were very useful to investigate the capacity of composite structures subjected to large inelastic excursions. Under the dominant load combination 
(LC 5), the resulting pushover curves were plotted as inter-story drift ratios (ISDR: $\Delta / H$ ) at the roof story vs. the base shear force normalized by the design base shear force $\left(\mathrm{V}_{\text {Base }} / \mathrm{V}_{\text {Design }}\right)$, as shown in Figures 11 (a) and (b). These figures show comparisons of pushover curves for composite frames with the same composite column systems but different connection types (e.g. 6PRT-RC vs. 6FRW-RC).
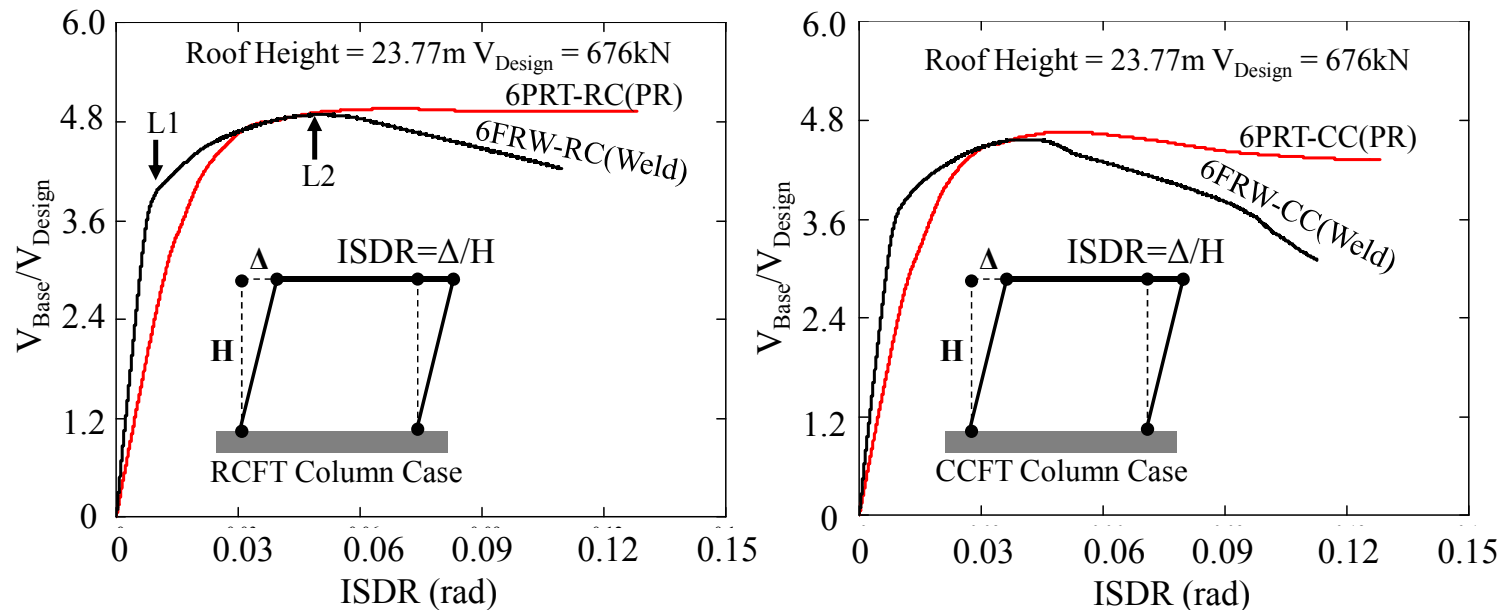

(a) Nonlinear Monotonic Pushover Analysis
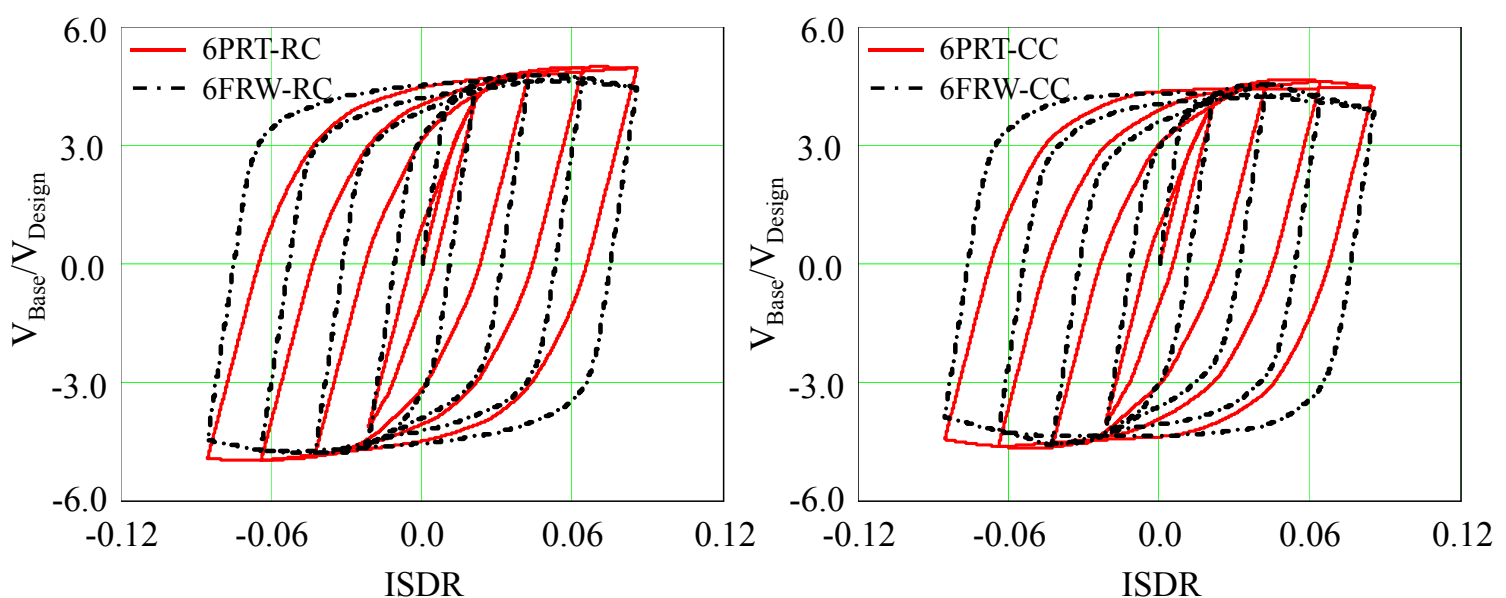

(b) Nonlinear Cyclic Pushover Analysis

Figures 11 (a) and (b). Results of Nonlinear Pushover Analyses

The elastic range (proportional limit), yield strength (L1), initiation of hardening, ultimate strength (L2), and strength degradation or stability limit can be observed in the static nonlinear pushover curves (see Figure 11 (a)). The 6PRT models with SMA PR-CFT connections show a more flexible initial slope than the 6FRW models with welded FR connections. The stiffness loss due to slip at the bolt holes and the inherent characteristics of the PR connections can cause the C-PRMF to have relatively lower initial stiffness. After arriving at the ultimate strength (L2), the strength of the 6PRT models deteriorated more slowly than that of the counterpart FR model. This indicates that PR connections with more flexible tension bars provide more ductility. The frames with welded connections are susceptible to collapse due to brittle fracture of welded sections and larger P-Delta effects. Therefore, faster strength degradation was observed in the pushover curves of welded moment frames (6FRW models).

Energy dissipation, unloading slope, and permanent displacements can be observed during cyclic pushover analyses (Figure 11 (b)). As we expected, all transition points on the envelope of the monotonic curve coincided with those on the envelope of the cyclic curves when the same models 
are tested. Similarly, strength degradations were found in the cyclic behavior of 6FRW models after their ultimate strength was exceeded. This caused a decrease in energy dissipation capacity. Due to the recentering capacities of SMA tension bars, 6PRT models show a smaller permanent roof displacement during unloading than 6FRW models.

\subsection{Nonlinear Dynamic Analyses}

As shown in Figure 12, the LA 21 ground motion with 6.9 magnitude and 60 second duration was chosen to examine the seismic response of the overall structure for two frame systems (6PRT vs. 6FRW). This ground motion was scaled to $1.283 \mathrm{~g}$ peak ground acceleration (PGA). The time-histories for the roof story displacement and the normalized base shear vs. ISDR plots at the roof level are shown in Figures 13 (a) and (b).

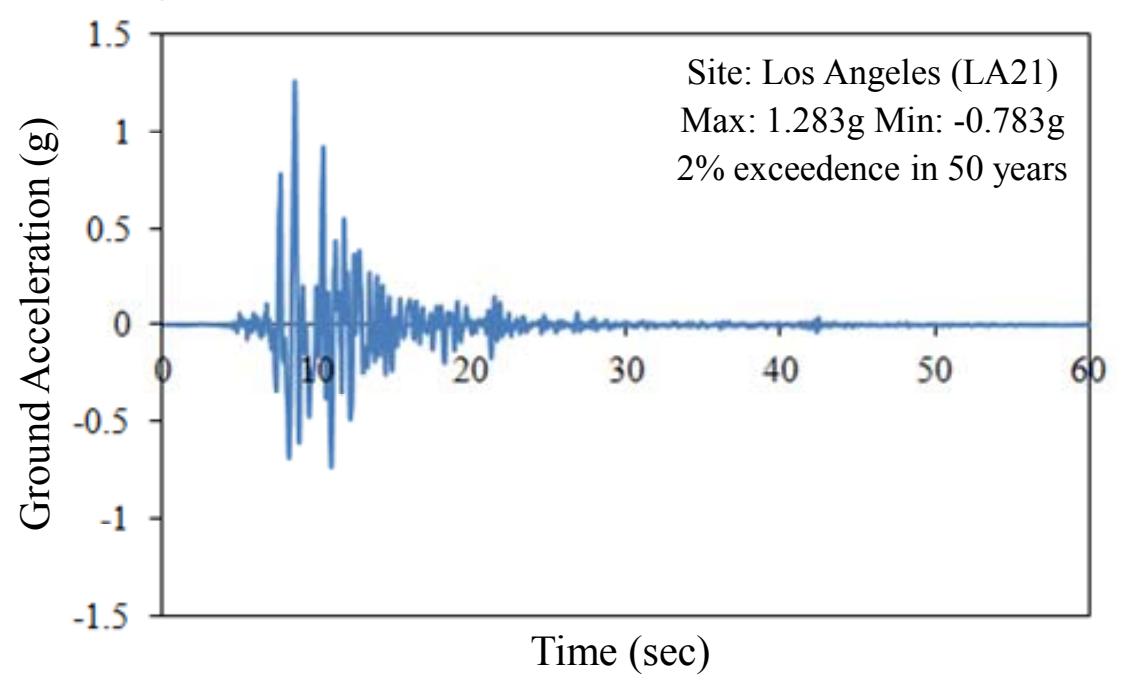

Figure 12. Ground Motion used for Nonlinear Dynamic Time-history Analyses

The peak roof displacements for the 6PRT-RC and 6FRT-RC models are about $590 \mathrm{~mm}$ and 450 $\mathrm{mm}$, which indicate a roof ISDR of $2.5 \%$ and $1.9 \%$, respectively (see Figure 13 (a)). The flexibility of the PR connections and the recentering effect of the SMA tension bars enabled the roof displacement to be reduced by approximately $25 \%$. Note that the 6PRT models have a permanent roof displacement of approximately $30 \mathrm{~mm}$, while the 6FRW models have approximately $200 \mathrm{~mm}$ at the final time step $(60 \mathrm{sec}$.). This implies that SE SMA components are able to reduce permanent displacement and limit damage to the structural systems. Furthermore, a smaller peak roof ISDR corresponding to relatively higher peak normalized shear was observed for the 6PRT models as compared to the 6FRW models (see Figure 13 (b)). For instance, a peak roof ISDR of $1.9 \%$ corresponding to the normalized base shear of $\mathrm{V}_{\text {Base }} / \mathrm{V}_{\text {Design }}=4.5$ occurs in the 6PRT-RC model, while a peak roof ISDR of $2.5 \%$ corresponding to the normalized base shear of $\mathrm{V}_{\text {Base }} / \mathrm{V}_{\text {Design }}=4.05$ occurred in the 6FRW-RC model. The superior ability of SMA PR-CFT connections, which provides gentle strength degradation in the pushover behavior, allowed the 6PRT models to undergo strong ground motions with relatively smaller ISDR rather than the 6FRW models. 

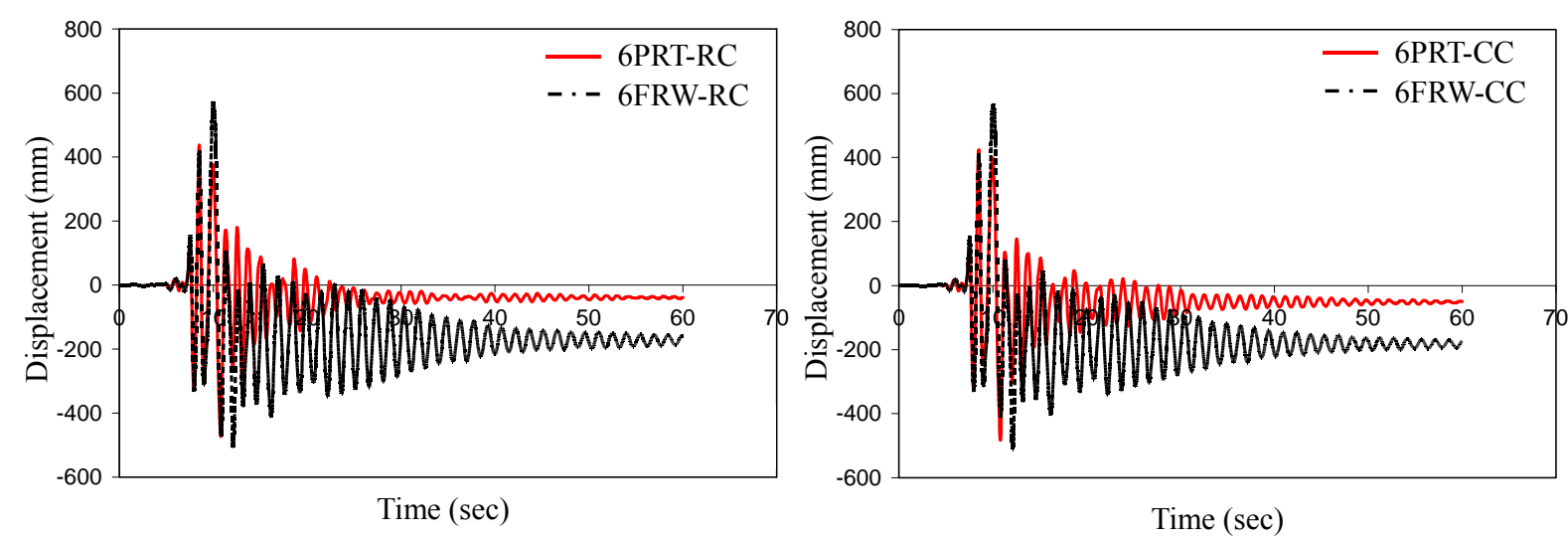

(a) Time vs. Displacement at the roof

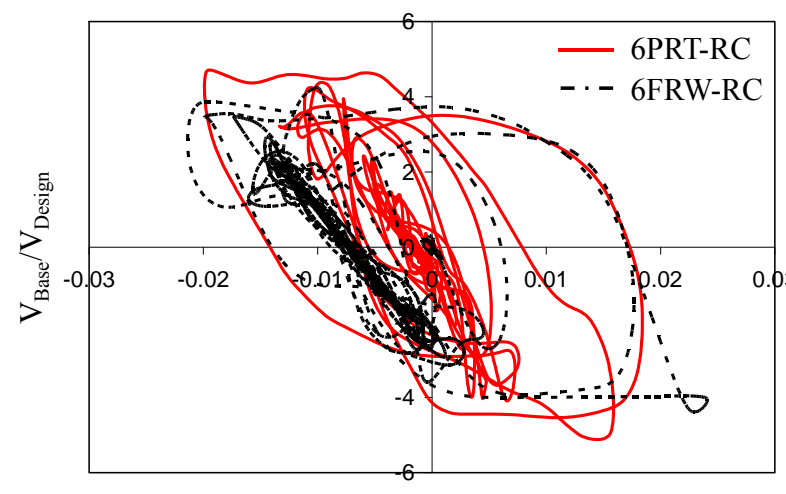

ISDR

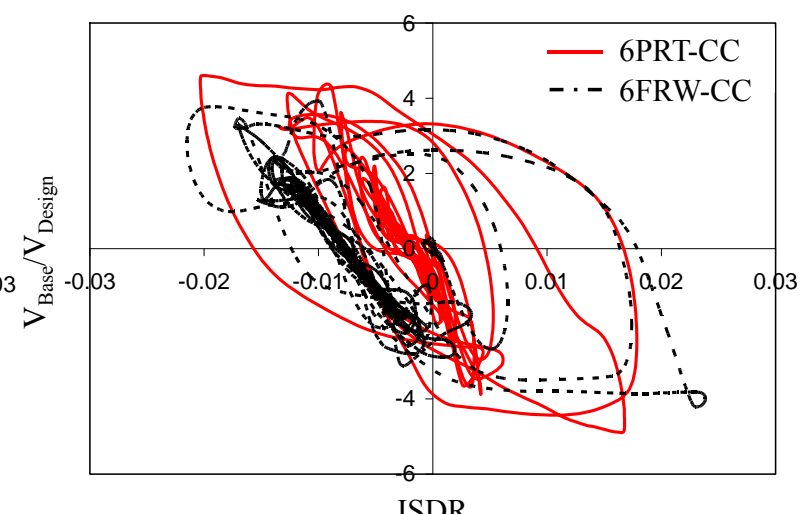

(b) Normalized Base Shear vs. ISDR at the roof

Figures 13 (a) and (b). Results of Nonlinear Dynamic Time-history Analyses

\section{CONCLUSIONS}

The main conclusions of this study are as follows:

- The proposed joint element includes behavioral properties of the components in the form of a simplified model that reflects the global stiffness, strength, and deformation capacity of the actual connection. This type of joint model results in significant savings in running time for frame analyses.

- Four different prototypes of composite perimeter moment frames with either PR connections or FR connections were presented in this study. 2D numerical frame models were used in nonlinear frame analyses. The behavior of the composite PR connections was successfully simulated using 2D joint elements developed in this study.

- Based on pushover analysis results, composite moment frames with PR connections showed smaller residual displacements than those with welded connections due to the recentering effect of the SMA components. In addition, composite frames with PR connections showed a more gradual degradation in strength.

- From nonlinear dynamic analysis results, composite moment frames with welded connections showed larger peak roof displacements. The outstanding energy dissipation properties of the PR connections resulted in lower drifts. Finally, it can be concluded that composite PR moment frames show superior performance owing to structural advantages for the proposed connection models in comparison with traditional welded ones. 


\section{ACKNOWLEDGEMENTS}

This research was supported by Basic Science Research Program through the National Research Foundation of Korea (NRF) funded by the Ministry of Education, Science and Technology (Grant No. 2012R1A1A1041521). The author (J.W. Hu) gratefully acknowledges this support. The author also sincerely thanks Prof. Roberto T. Leon for his academic advice and valuable comments when he was a Ph.D. student and Post-Doctoral Fellow at Georgia Tech.

\section{REFERENCES}

[1] Tsai, K.C., Hsiao, P.C., Wang, K.J., Weng, Y.T., Hsia, P.C., Lin, K.C., Chen, C.H., Lai, J.W., and Lin, S.L., "Pseudo-dynamic Tests of a Full-scale CFT/BRB Frame-Part I: Specimen Design, Experiment and Analysis", Earthquake Engineering and Structural Dynamics, 2008, Vol. 37, pp. 1081-1098.

[2] Wu, L., Chung, L.L., Tsai, S.F., Lu, C.F., and Huang, G.L., "Seismic Behavior of Bidirectional Bolted Connections for CFT Columns and H-beams", Engineering Structures, 2008, Vol. 29, No. 3, pp. 395-407.

[3] American Institute of Steel Construction (AISC), Seismic Provisions for Structural Steel Buildings (ANSI/AISC 341-05), 2005, Chicago, IL.

[4] American Society of Civil Engineers (ASCE), Minimum Design Loads for Buildings and Other Structures (ASCE 7-05), 2002, Reston, VA.

[5] Wu, L.Y., Chung, L.L., Tsai, S.F., Lu, C.F., and Huang, G.L., "Seismic Behavior of Bolted Beam to Column Connections for Concrete Filled Steel Tube", Journal of Constructional Steel Research, 2005, Vol. 61, No. 10, pp. 1387-1410.

[6] Park, T., Hwang, W.S., and Hu, J.W., "Damage Evaluation of Composite-special Moment Frames with Concrete-filled Tube Columns under Strong Seismic Loads", KSCE Journal of Civil Engineering, 2011, Vol. 15, No. 8, pp. 1381-1394.

[7] Hu, J.W., Kang, Y.G., Choi, D.H., and Park, T., "Seismic Design and Behavior of Composite-moment Frames with Steel Beam-to-concrete Filled Tube Column Connections", KSSC International Journal of Steel Structures, 2010, Vol. 10, No. 2, pp. 177-191.

[8] Hu, J.W., Park, J., and Leon, R.T., "Advanced Analysis and Performance based Evaluation of Concrete Filled Tube (CFT) Columns", International Journal of Advanced Steel Construction, 2010, Vol. 6, No. 4, pp. 1018-1032.

[9] Leon, R.T., "Seismic Performance of Bolted and Riveted Connections, Background Reports: Metallugy, Fracture Mechanics, Welding, Moment Connections, and Frame System Behavior", FEMA Publication No. 288 Federal Emergency Management Association (FEMA), Washington (DC), 1997.

[10] Green, T.P., Leon, R.T., and Rassati, G.A., "Bidirectional Tests on Partially Restrained, Composite Beam-column Connections", ASCE Journal of Structural Engineering, 2004, Vol. 130, No. 2, pp. 320-327.

[11] Rassati, G.A., Leon, R.T., and Noe, S., "Component Modeling of Partially Restrained Composite Joints under Cyclic and Dynamic Loading", ASCE Journal of Structural Engineering, 2004, Vol. 130, No. 2, pp. 343-351.

[12] Penar, B.W., "Recentering Beam-column Connections using Shape Memory Alloys", Master's Thesis, 2005, Georgia Institute of Technology, 2005.

[13] Hu, J. W., "Seismic Performance Evaluations and Analyses for Composite Moment Frames with Smart SMA PR-CFT Connections", Ph.D. Dissertation, Georgia Institute of Technology, 2008. 
[14] DesRoches, R., McCormick, J., and Delemont, M., "Cyclic Properties of Superelasic Shape Memory Alloy Wires and Bars", ASCE Journal of Structural Engineering, 2004, Vol.130, No.5, pp. 732-740.

[15] Mazzoni, S., Mckenna, F., and Fenves, G.L., "OpenSEES Command Language Manual v. 1.7.3., Department of Civil Environmental Engineering”, University of California at Berkley, 2006.

[16] Braconi, A., Salvatore, W., Tremblay, R., and Bursi, O.S., "Behaviour and Modelling of Partial-strength Beam-to-column Composite Joints for Seismic Applications", Earthquake Engineering and Structural Dynamics, 2007, Vol. 36, pp. 142-161.

[17] Kulak, G.L., Fisher, J.W., and Struik, J.H.A., "Guide to Design Criteria for Bolted and Riveted Joint", $2^{\text {nd }}$ Edition, Johns Wiley \& Sons, 1987.

[18] Rex, C.O., and Easterling, W.S., "Behavior and Modeling of a Single Plate Bearing on a Single Bolt", Report No. CE/VPI-ST 96/14, Virginia Polytechnic Institute and State University, Blacksburg, VA, 1996.

[19] Astaneh-Asl, A., "Seismic Design of Bolted Steel Moment-resisting Frames", Technical Informational \& Product Service, 1995.

[20] Hu, J.W., Leon, R.T., and Park, T., "Analytical Investigation on Ultimate Behaviors for Steel Heavy Clip-angle Connections using FE Analysis”, ISIJ International, 2010, Vol. 50, No. 6, pp. 883-892.

[21] Swanson, J.A., "Characterization of the Strength, Stiffness, and Ductility Behavior of T-stub Connection”, Ph.D. Dissertation, Georgia Institute of Technology, 1999.

[22] Swanson, J.A., "Ultimate Strength Prying Models for Bolted T-stub Connections", AISC Engineering Journal, 2002, Vol. 39, No. 3, pp. 136-147.

[23] Davide, F., "Shape Alloy Devices in Earthquake Engineering: Mechanical Properties, Constitutive Modeling and Numerical Simulations", Master's Thesis, Rose School in Italy, 2003.

[24] International Code Council (ICC), International Building Code (IBC 2003), Falls Church, VA, 2003.

[25] American Institute of Steel Construction (AISC), Manual of Steel Construction: Load and Resistance Factor Design (LRFD), $3^{\text {rd }}$ Edition, Chicago, IL, 2001.

[26] Somerville, P. G., Smith, N., Punyamurthula, S., and Sun, J., "Development of Ground Motion Time Histories for Phase 2 of the FEMA/SAC Steel Project", Report No.SAC/BD 97/04, SAC Background Document, 1997.

[27] Newmark, N.M., "A Method of Computation for Structural Dynamics", ASCE Journal of Engineering Mechanics Division, 1959, Vol. 85, No. 3. 